OPEN ACCESS

Edited by:

Robert Allan,

University of Central Lancashire,

United Kingdom

Reviewed by:

Toby Mündel,

Massey University, New Zealand Jeffrey William Frederick Aldous,

University of Bedfordshire,

United Kingdom

*Correspondence:

Afton D. Seeley

afton.d.seeley.ctr@mail.mil

Specialty section:

This article was submitted to

Elite Sports and Performance

Enhancement,

a section of the journal

Frontiers in Sports and Active Living

Received: 29 January 2021 Accepted: 29 March 2021

Published: 29 April 2021

Citation:

Seeley AD and Sherman RA (2021) An Ice Vest, but Not Single-Hand Cooling, Is Effective at Reducing Thermo-Physiological Strain During Exercise Recovery in the Heat. Front. Sports Act. Living 3:660910. doi: 10.3389/fspor.2021.660910

\section{An Ice Vest, but Not Single-Hand Cooling, Is Effective at Reducing Thermo-Physiological Strain During Exercise Recovery in the Heat}

\author{
Afton D. Seeley ${ }^{1,2,3 *}$ and Ross A. Sherman ${ }^{4}$ \\ ${ }^{1}$ Department of Human Performance and Health Education, Western Michigan University, Kalamazoo, MI, United States, \\ 2 Thermal and Mountain Medicine Division, US Army Research Institute of Environmental Medicine, Natick, MA, \\ United States, ${ }^{3}$ Oak Ridge Institute of Science and Education, Belcamp, MD, United States, ${ }^{4}$ Department of Movement \\ Science, Grand Valley State University, Allendale, MI, United States
}

Sports limit the length of breaks between halves or periods, placing substantial time constraints on cooling effectiveness. This study investigated the effect of active cooling during both time-limited and prolonged post-exercise recovery in the heat. Ten recreationally-active adults $\left(\mathrm{VO}_{2 \text { peak }} 43.6 \pm 7.5 \mathrm{ml} \cdot \mathrm{kg}^{-1} \cdot \mathrm{min}^{-1}\right)$ were exposed to thermally-challenging conditions $\left(36^{\circ} \mathrm{C}\right.$ air temperature, $\left.45 \% \mathrm{RH}\right)$ while passively seated for $30 \mathrm{~min}$, cycling for $60 \mathrm{~min}$ at $51 \% \mathrm{VO}_{2 \text { peak }}$, and during a seated recovery for $60 \mathrm{~min}$ that was broken into two epochs: first 15 min $\left(R^{2} C_{0-15}\right)$ and total 60 min $\left(R C_{0}-60\right)$. Three different cooling techniques were implemented during independent recovery trials: (a) negative-pressure single hand-cooling $\left(\sim 17^{\circ} \mathrm{C}\right)$; (b) ice vest; and (c) non-cooling control. Change in rectal temperature $\left(T_{\text {re }}\right)$, mean skin temperature $\left(\bar{T}_{\text {sk }}\right)$, heart rate $(\mathrm{HR})$, and thermal sensation (TS), as well as mean body temperature $\left(\bar{T}_{\mathrm{b}}\right)$, and heat storage $(S)$ were calculated for exercise, $\mathrm{REC}_{0-15}$ and $\mathrm{REC}_{0-60}$. During $\mathrm{REC}_{0-15}, \mathrm{HR}$ was lowered more with the ice vest $(-9$ [-15 to -3$]$ bts $\left.\cdot \mathrm{min}^{-1}, p=0.002\right)$ and single hand-cooling $(-7$ [ -13 to -1$]$ bts. $\left.\min ^{-1}, p=0.021\right)$ compared to a non-cooling control. The ice vest caused a greater change in $\bar{T}_{\text {sk }}$ compared to no cooling $\left(-1.07[-2.00 \text { to }-0.13]^{\circ} \mathrm{C}\right.$, $p=0.021)$ and single-hand cooling $\left(-1.07[-2.01 \text { to }-0.14]^{\circ} \mathrm{C}, p=0.020\right)$, as well as a greater change in $S$ compared to no cooling $(-84[-132$ to -37$] \mathrm{W}, p<0.0001)$ and single-hand cooling $(-74[-125$ to -24$] \mathrm{W}, p=0.002)$. Across $\mathrm{REC}_{0-60}$, changes in $\bar{T}_{\mathrm{b}}$ $\left(-0.38[-0.69 \text { to }-0.07]^{\circ} \mathrm{C}, p=0.012\right)$ and $\bar{T}_{\text {sk }}\left(-1.62[-2.56 \text { to }-0.68]^{\circ} \mathrm{C}, p<0.0001\right)$ were greater with ice vest compared to no cooling. Furthermore, changes in in $\bar{T}_{\mathrm{b}}(-0.39$ $\left.[-0.70 \text { to }-0.08]^{\circ} \mathrm{C}, p=0.010\right)$ and $\bar{T}_{\text {sk }}\left(-1.68[-2.61 \text { to }-0.74]^{\circ} \mathrm{C}, p<0.0001\right)$ were greater with the ice vest compared to single-hand cooling. Using an ice vest during time-limited and prolonged recovery in the heat aided in a more effective reduction in thermo-physiological strain compared to both passive cooling as well as a single-hand cooling device.

Keywords: exercise in heat, thermoregulation, post-exercise recovery, skin temperature, heat storage, core temperature, sport 


\section{INTRODUCTION}

Both professional and recreational sporting events frequently take place in thermally-stressful environments, including the familiar summer Olympic Games (Barwood et al., 2009). Unabated heat gain during exercise performed in hot environments, the product of both elevated muscular work and a reduced skin temperature to ambient temperature $\left(T_{\mathrm{sk}}-T_{\mathrm{a}}\right)$, and therefore core temperature to skin temperature $\left(T_{\mathrm{c}}-T_{\mathrm{sk}}\right)$, thermal exchange gradient, is capable of eliciting hyperthermic core body temperatures $\left(T_{\mathrm{c}}\right)>39^{\circ} \mathrm{C}$ (Wendt et al., 2007). Heated exercise-induced core and skin temperatures elevations contribute to the deterioration of aerobic exercise capacity, although the exact cardiovascular mechanisms by which this decrement occurs appears to be a function of both exercise intensity and duration (Nybo et al., 2011). At maximal exercise intensities, augmentation of skin blood flow to facilitate heat loss impairs cardiac filling, reducing central venous pressure, and maximal cardiac output, and therefore competitively impairs arterial oxygen delivery to exercising skeletal muscle. At prolonged submaximal intensities when muscle blood flow and oxygen consumption are often not significantly changed relative to a more temperate environment, high skin temperatures likely influence the perception of fatigue via alterations in afferent feedback (Nybo et al., 2011). Continually increasing core and skin temperatures, especially during prolonged exercise, additionally pose an enhanced likelihood of heat illness. Heat stroke, the most serious heat related syndrome, is designated by a severely elevated core temperature and failure of an individual's sweating mechanisms (Coris et al., 2004).

Athletes that participate in outdoor sporting events of a prolonged heated nature, such as ultramarathons, and those with a limited $10-15 \mathrm{~min}$ half-time, such as soccer and rugby, may be especially susceptible to the deleterious influence of hyperthermia. Strategic pre-exercise behaviors including heat acclimation (Lorenzo et al., 2010) and intraexercise hydration strategies (Montain and Coyle, 1992; Travers et al., 2020) have proven helpful to reduce the physiological stress and performance decrement induced by hyperthermia. Furthermore, athletes engaging in prolonged or limited breaking sport have the potential to both offset aerobic performance decrement as well as the risk of heat illness by implementing efficient cooling strategies available during sporting breaks. While application of cooling devices in a continually heated environment may influence overall cooling effectiveness, sport, and occupational requirements often impede the removal of a hyperthermic individual from a heated environment. Furthermore, the implementation of techniques such as wholebody cold water immersion, deemed to be most efficient for thermoregulatory recovery (Casa et al., 2015; Zhang et al., 2015), is practically difficult in prophylactic cooling scenarios. Additionally, neck cooling, although effective in reducing the perception of heat strain (Sunderland et al., 2015), does not appear to meaningfully assist in thermo-physiological rebound from hyperthermia (Tyler and Sunderland, 2011; Sunderland et al., 2015). Therefore, using more practical and physiologyinfluencing cooling techniques during heated endurance exercise recovery, if deemed time-efficient in their cooling, may help to offset decrement of discontinuous aerobic exercise performance and the accumulated risk of severe heat illness.

Numerous commercially available small and portable cooling devices have been proposed to reduce cardiovascular strain, skin temperature, and core temperature following exerciseinduced hyperthermia.

A phase-changing "ice" vest provides a widened $T_{\mathrm{c}}-T_{\text {sk }}$ gradient, by reducing skin temperature, which favors heat loss from the blood perfusing the skin. The cooled blood then circulates back to the core, effectively contributing to the maintenance or development of a negative heat balance (House et al., 2013). The donning of an ice vest in occupational situations beneath clothing has effectively demonstrated reductions in heat strain (House, 1996; Cadarette et al., 2002; House et al., 2003; Amorim et al., 2010). The use of ice vests by hyperthermic athletes post-exercise, though, has proven less successful in reducing core temperature, with studies citing a loss in evaporative cooling with the torso encompassing vests (House et al., 2013).

Additional post-exercise cooling efforts have monopolized on hand cooling technologies some of which utilize a rigid chamber with a flexible airtight vacuum-seal about the wrist. Hand cooling is thought to optimize the loss of body heat through the arteriovenous anastomoses (AVAs) present in the palm, effectively dissipating heat at elevated core and skin temperatures (Bergersen, 1993). Battery powered cooling devices create a thermal gradient with the palm while the negative pressure in the vacuum chamber draws a large volume of blood into the AVAs to speed heat exchange and prevent cold-reactive vasoconstriction (Zhang et al., 2009). Research has focused largely on the use of this relatively light and portable hand cooling device during exercise (Grahn et al., 2005, 2012; Hsu et al., 2005), with only a small and inconclusive body of support for single-hand use in recovery (Zhang et al., 2009; Kuennen et al., 2010). One of the most recent investigations, using a commercially available hand cooling device (Adams et al., 2016) following heated treadmill exercise, suggests that dual hand cooling may reduce $T_{\text {re }}$ more than passive cooling alone, bolstering similar conclusions drawn from dual hand immersion in a simpler cold water bath (Barwood et al., 2009). Yet still, a variety of literature suggests a lack of advantageous core temperature reduction with administration of a single hand cooling device during exercise recovery (Balldin et al., 2007; Walker et al., 2009; Amorim et al., 2010).

Existing literature suggests augmented cooling by single-hand cooling when heavy heat retardant clothing is worn/retained following heated exercise and into heated recovery (Kuennen et al., 2010) and/or when hand cooling is imposed simultaneously with removal from the heated environment (Zhang et al., 2009). Furthermore, dual hand cooling, although much more logistically burdensome to dexterity, appears efficacious to efficiently reduce core temperature following heated exercise, likely due to the heightened cooling exposed skin surface area (Barwood et al., 2009; Adams et al., 2016). Still, little literature exists regarding the influence of a negative pressure hand cooling device on a sport-mimicking recovery environment where minimal clothing (shorts and t-shirt) is worn, individuals are not removed from 
the heated environment following exercise, and only single-hand cooling is utilized to retain dexterity.

The primary aim of this study is to investigate the effectiveness of active vs. passive cooling during time-limited and prolonged recovery in sport-mimicking conditions (minimal clothing, continued exposure to heat, dexterity maintenance) following submaximal exercise in the heat. A secondary aim of this study is to examine thermo-physiological and perceptual differences during recovery in the heat between negative pressure singlehand cooling and an ice vest. We hypothesized that active post-exercise cooling would significantly improve thermophysiological function and perceived thermal sensation (TS) in both time-limited and prolonged recovery. Additionally, it was proposed that an ice vest would be a more effective cooling strategy than single-hand cooling.

\section{MATERIALS AND METHODS}

\section{Participants and Procedural Controls}

Ten recreationally active participants (six males, four females, age $25 \pm 3$ years, body mass $75.5 \pm 12.5 \mathrm{~kg}$, height $173 \pm$ $9 \mathrm{~cm}, \mathrm{VO}_{2 \text { peak }} 43.6 \pm 7.5 \mathrm{ml} \cdot \mathrm{kg}^{-1} \cdot \mathrm{min}^{-1}$ ) participated in the study. All participants met the following inclusionary criteria: non-smoker; healthy, free of disease, and free of medication use which may affect the cardiovascular or metabolic responses during exercise; free of any orthopedic injuries or conditions that would make exercise difficult; classified as "Low Risk" by the American College of Sport Medicine (Pescatello et al., 2014); and not obese (body mass index $<30 \mathrm{~kg} \cdot \mathrm{m}^{-2}$ ). Participants gave written, informed consent prior to participation in the study, which had been approved by the Human Subjects Institutional Review Board (Project Approval Number: 13-12-10) at Western Michigan University.

Participants were asked to refrain from ingesting any caffeine and engaging in exercise the day of the visits to the laboratory. Eumenorrhoeic female participants were asked to self-report the date of last menses to restrict collection of thermoregulatory data only within the early follicular phase (cycle days 3-6). Those that reported using a biphasic oral contraceptive $(n=1)$ were tested within the first 3-6 days of active pills following the withdrawal week, in an attempt to minimize the day-to-day variability in thermoregulatory variables, especially rectal temperature (Lei et al., 2019). Notably, pre-exercise rectal temperature did not significantly differ between conditions (control: $37.13 \pm 0.30$, ice vest: $37.23 \pm 0.28$, single-hand cooling: $37.17 \pm 0.30, p=0.734$ ). Each participant was asked to wear a t-shirt, shorts, socks, and athletic shoes each time they visited the laboratory. All trials for a given participant were conducted during the morning $( \pm 1 \mathrm{~h})$ to avoid diurnal variation in core temperature (Morris et al., 2009). The research was conducted outside of the summer months (September-April) in order to minimize any seasonal heat acclimation. Furthermore, all heated trials were separated by at least 1 week to minimize the likelihood of induced heat acclimation.

\section{Research Design}

The study was conducted utilizing a randomized counterbalanced cross-over design with three recovery conditions: (1) negative pressure single-hand cooling, (2) ice vest, and (3) a non-cooling control. Participants visited the laboratory on four separate occasions. The first visit consisted of a graded exercise test and the following three visits consisted of exercise bouts in the heat followed by one of the three recovery cooling conditions.

\section{Graded Exercise Test}

Upon arrival to the laboratory, height and body mass were measured using standardized techniques and a wall-mounted stadiometer and digital scale, respectively. Each participant completed a graded exercise test on an electromagneticallybraked cycle ergometer (Corival, Lode B.V., Groningen, Netherlands) to determine peak oxygen consumption $\left(\mathrm{VO}_{2 \text { peak }}\right)$ as a measure of cardiorespiratory fitness. The $\mathrm{VO}_{2 \text { peak }}$ value obtained allowed determination of the appropriate exercise intensity $\left(\sim 50 \% \mathrm{VO}_{2 \text { peak }}\right)$ for all experimental trials. Each participant was fitted for seat height on the cycle ergometer, with the participant's knee at $10-15^{\circ}$ of flexion at the pedal's lowest point. Additionally, each participant was fitted with a nose clip and a mouthpiece for the collection of 15-s averaged expired respiratory gases using a metabolic cart (TrueOne 2400, ParvoMedics, Sandy, UT), and a heart rate (HR) monitor (Polar USA, Lake Success, Long Island, NY). The assessment consisted of a graded protocol that began with two- min of cycling at $40 \mathrm{~W}$ for female and $60 \mathrm{~W}$ for male participants. The cycling intensity was increased every minute thereafter by $20 \mathrm{~W}$ until volitional fatigue. Volitional fatigue was determined as the point during exercise when each participant felt like they could exercise no longer or could no longer maintain a pedaling frequency of at least $50 \mathrm{rpm}$. Each participant was asked to assess their ratings of perceived exertion (RPE) using a standard 6-20 scale (Borg and Linderholm, 1967) during the last $30 \mathrm{~s}$ of each stage. Once the exercise test protocol was terminated, each participant was provided water ad libitum and continued to cycle at a low intensity for 5-10 min whilst being monitored for normal, post-exercise cardiovascular recovery.

\section{Experimental Trials}

Upon arrival at the laboratory, participants' nude body mass was measured. Thirty minutes prior to entering the heated $\left(36^{\circ} \mathrm{C}, 45 \% \mathrm{RH}\right)$ environmental chamber (Thermotron, Holland, MI) a bolus of plain water equivalent to $5 \mathrm{ml} \cdot \mathrm{kg}^{-1}$ body mass was administered in an attempt to standardize pre-exercise hydration status. A flexible probe (Physitemp Instruments Inc., Clifton, NJ) was inserted $13 \mathrm{~cm}$ past the anal sphincter for the measurement of rectal temperature $\left(T_{\text {re }}\right)$. Thermocouples (Physitemp Instruments Inc., Clifton, NJ) were also attached to the surface of the skin at four sites on the right side of the body (chest, triceps, quadriceps, calf) using waterproof tape (Hy-tape, Hytape International Inc., Patterson, NY) for the measurement of skin temperature $\left(T_{\text {sk }}\right)$. The four sites contributed to the calculation of mean skin temperature ( $\bar{T}_{\text {sk }}$; Ramanathan, 1964):

$$
\bar{T}_{\text {sk }}=0.3\left(T_{\text {chest }}+T_{\text {arm }}\right)+0.2\left(T_{\text {thigh }}+T_{\text {calf }}\right)
$$


Both $T_{\text {re }}$ and $\bar{T}_{\text {sk }}$ were then used to calculate mean body temperature $\left(\bar{T}_{\mathrm{b}}\right.$; Colin and Houdas, 1965$)$ :

$$
\bar{T}_{\mathrm{b}}=\left(0.8 \cdot T_{\mathrm{re}}\right)+\left(0.2 \cdot \bar{T}_{\mathrm{sk}}\right)
$$

Stored heat $(S)$ was calculated for the exercise bout and recovery using the following equation:

$$
S=\Delta \bar{T}_{\mathrm{b}} \cdot 3.48 \cdot \mathrm{mass} / \mathrm{t}
$$

where: $\Delta \bar{T}_{\mathrm{b}}=$ change in mean body temperature, the average specific heat of body tissues was assumed as $3.48 \mathrm{~kJ} \cdot \mathrm{kg}^{-1} \cdot{ }^{\circ} \mathrm{C}^{-1}$, mass $=$ pre-test mass of the participant $(\mathrm{kg}), t=$ time $(\mathrm{s})$.

Rectal and skin thermocouples were connected to a data acquisition system (Thermes USB, Physitemp Instruments Inc., Clifton, NJ) that was interfaced to a PC computer. Lastly, a HR monitor was fitted.

Each trial consisted of the following sequence performed entirely within the environmental chamber at $36^{\circ} \mathrm{C}, 45 \% \mathrm{RH}$ :

- 30 min of seated rest

- 60 min of cycling at $\sim 50 \% \mathrm{VO}_{2 \text { peak }}$ or until $T_{\text {re }} \geq 39.5^{\circ} \mathrm{C}$

- 60 min of seated rest with one of the cooling conditions.

Time to complete this trial sequence within the environmental chamber across all conditions was $154.12 \pm 1.26 \mathrm{~min}$. Each participant's target exercise $\mathrm{VO}_{2}$ and starting power output was determined utilizing the established power output to $\mathrm{VO}_{2}$ relationship determined using the $\mathrm{VO}_{2 \text { peak }}$ assessment. During each participant's first trial, expired respiratory gases were collected during the first $10 \mathrm{~min}$ of exercise. If the 15-s averaged $\mathrm{VO}_{2}$ from 5:15 to 7:00 after the start of exercise was not $50 \pm$ $5 \% \mathrm{VO}_{2 \text { peak }}$, the intensity was adjusted in $5 \mathrm{~W}$ increments until target $\mathrm{VO}_{2}$ was reached. Exercise intensity was monitored for an additional 2 min upon readjustment to ensure $\mathrm{VO}_{2}$ stability. The progression of exercise intensity for each subsequent trial followed an identical scheme: (1) 2-min warm-up at half of the $50 \% \mathrm{VO}_{2 \text { peak }}$ power output, (2) at $2 \mathrm{~min}$, the intensity was increased to the $50 \% \mathrm{VO}_{2 \text { peak }}$ eliciting power output, and if needed (3) power output was adjusted from 7 to $10 \mathrm{~min}$ of exercise.

Both $T_{\text {re }}$ and $T_{\text {sk }}$ were continuously monitored throughout all phases of each trial. $T_{\text {re }}$ and $T_{\text {sk }}$ were recorded during the last $5 \mathrm{~min}$ of passive rest, and every $5 \mathrm{~min}$ during exercise and recovery. Participants were also asked to assess their TS using a standard 0-8 scale (Gagge et al., 1967) during the last $5 \mathrm{~min}$ of passive rest, and every $5 \mathrm{~min}$ during exercise and recovery. Participants were prevented from ingesting any fluids throughout the full duration of each trial (start of passive rest through to the end of recovery). Nude body mass was again measured immediately after the end of recovery in each trial to allow for the determination of fluid loss via change in nude body mass.

\section{Recovery Phase}

The $60 \mathrm{~min}$ post-exercise seated rest portion of the study $\left(\right.$ REC $\left._{0-60}\right)$, where each of the three cooling interventions was applied while within $36^{\circ} \mathrm{C}, 45 \% \mathrm{RH}$ conditions based on the randomized order, was split into two epochs; the first time-limited, $15 \mathrm{~min}$ recovery period $\left(\mathrm{REC}_{0-15}\right)$ and the prolonged $60 \mathrm{~min}$ recovery period $\left(\mathrm{REC}_{0-60}\right)$ to allow for shortand long-term responses to be monitored and assessed. The control condition consisted of passive seated recovery following exercise cessation and had participants sit quietly with minimal movement in a backed chair with their feet planted on the floor.

\section{Hand Cooling}

The hand cooling device (CoreControl, AVAcore Technologies, Ann Arbor, MI) was administered with participants seated in a backed chair, and fixed to the dominant hand and forearm. Participants were instructed to place their hand over the small soft disc at the bottom of the device to ensure standardized exposure. Using a water-dwelling thermometer, the temperature of the continuously perfusing water was maintained at $\sim 17^{\circ} \mathrm{C}$ with the addition of more ice to the slurry mix when necessary. The device also used a low pressure $(\sim 15 \mathrm{mmHg})$ vacuum around the forearm to facilitate blood transport through the AVAs and prevent acute vasoconstriction. This low pressure vacuum was maintained for the duration of the exposure.

\section{Ice Vest}

The ice vest (Kool Max Poncho Vest, Polar Products, Stow, Ohio) was adjustable to fit all torso sizes, and was equipped with frozen ice packs (Kool Max Ice Packs, Polar Products, Stow, Ohio) fixed in 10 individual pockets dispersed equally on the front and the back of the torso. Upon initial application, the temperature of the packs was $0^{\circ} \mathrm{C}$ with no attempt to control heat gain over the duration of application. Participants were seated in a backed chair with their feet planted on the floor.

\section{Statistical Analysis}

A one-way analysis of variance (ANOVA) was used to assess exercise differences in $\mathrm{VO}_{2}$, pre-post trial nude body mass, as well as change in $\bar{T}_{\mathrm{b}}, S, T_{\mathrm{re}}, \bar{T}_{\mathrm{sk}}, \mathrm{HR}$, and TS across the three experimental exercise trials. Normality of dependent variables was assessed using a Shapiro-Wilk test and sphericity for each main and interaction effect using Mauchly's sphericity test. Delta data for $\bar{T}_{\mathrm{b}}, S, T_{\mathrm{re}}, \bar{T}_{\mathrm{sk}}, \mathrm{HR}$, and TS from recovery baseline values were analyzed using linear mixed modeling with restricted maximum likelihood and Satterthwaite smallsample correction of degrees of freedom. The model had fixed factors of condition (control, ice vest, single-hand cooling), time $\left(\mathrm{REC}_{0-15}, \mathrm{REC}_{0-60}\right)$, and condition*time with a covariate (value at start of recovery) equal across conditions. The model included a random intercept by participant to account for the hierarchical data structure (repeated measures within participants). A secondary linear mixed model with baseline recovery covariate was conducted to further investigate $\mathrm{REC}_{0-15}$ components $\left(\mathrm{REC}_{0-5}, \mathrm{REC}_{5-10}, \mathrm{REC}_{10-15}\right)$ across conditions. For all statistical procedures, when appropriate, post-hoc pairwise comparisons were conducted using a Sidak correction to reduce Type I error. Statistical significance was set at $p<0.05$ for all analyses, and data was analyzed using IBM SPSS version 26.0 (IBM Corporation, Chicago, IL). All absolute data are presented as mean \pm standard deviation and all delta data are 
presented as mean difference with $95 \%$ confidence intervals where appropriate.

\section{RESULTS}

\section{Exercise in the Heat}

The $\mathrm{VO}_{2}$ averaged across all exercise bouts was $1.65 \pm 0.42$ $\mathrm{L} \cdot \mathrm{min}^{-1}\left(51 \pm 2 \% \mathrm{VO}_{2 \text { peak }}\right)$, which was elicited by $92 \pm$ $35 \mathrm{~W}$. No differences in $\mathrm{VO}_{2}$ existed between experimental trials $(p=0.483)$. Thermo-physiological responses were not different across the three exercise bouts in the heat, with similar heat storage (control: $89 \pm 35 \mathrm{~W}$, ice vest: $91 \pm$ $32 \mathrm{~W}$, single hand-cooling: $82 \pm 26 \mathrm{~W} ; p=0.297$ ) and endexercise $T_{\text {re }}$ (control: $38.28 \pm 0.31^{\circ} \mathrm{C}$, ice vest: $38.37 \pm 0.24^{\circ} \mathrm{C}$, single hand-cooling: $38.22 \pm 0.40^{\circ} \mathrm{C} ; p=0.250$ ) across the three trials.

\section{Post-exercise Recovery in the Heat Thermoregulation}

Stored heat (S) reduction during $\mathrm{REC}_{0-15}$ was different between cooling conditions, with the application of an ice vest eliciting a significantly greater reduction of stored heat across timelimited recovery $\left(\mathrm{REC}_{0-15}\right)$ compared to a non-cooling control $(-84[-132$ to -37$] \mathrm{W}, p<0.0001)$ and single-hand cooling $(-74[-125$ to -24$] \mathrm{W}, p=0.002)$. A deeper look into the components of time-limited recovery indicates that heat loss was increased across the first 5 min of ice vest application when compared to both control $(-44[-73$ to -15$] \mathrm{W}, p=0.001)$ and single-hand cooling ( $-31[-61$ to -0.3$] \mathrm{W}, p=0.047)$. Specifically for the ice vest recovery condition, the rate of heat loss was greater during the time-limited recovery than during prolonged recovery $(-69[-107$ to -31$] \mathrm{W}, p=0.001)$. Mean delta and individual data for $S$ can be found in Table 1 and Figure 1, respectively.

No differences between conditions existed with regards to $T_{\text {re }}$ reduction across time-limited or prolonged recovery $(p=0.990)$. Across all conditions, $T_{\text {re }}$ recovery was greater during $\mathrm{REC}_{0-60}$ compared to $\mathrm{REC}_{0-15}$ (control: $-0.45[-0.67 \text { to }-0.24]^{\circ} \mathrm{C}$, $p<0.0001$; ice vest: -0.47 [ -0.69 to -0.25$]^{\circ} \mathrm{C}, p<0.0001$; single-hand cooling: $-0.45[-0.67 \text { to }-0.23]^{\circ} \mathrm{C}, p<0.0001$ ), which was expected given the difference in total recovery length. However, $T_{\text {re }}$ recovery during $\mathrm{REC}_{0-15}$ accounted for $36 \%$ of the total $T_{\text {re }}$ reduction during the full $60 \mathrm{~min}$ recovery, while it only accounted for $32 \%$ of $T_{\text {re }}$ recovery for the control and singlehand cooling conditions. Interestingly, $T_{\text {re }}$ recovery with the ice vest condition was significantly larger across both $5-10 \mathrm{~min}$ $\left(-0.09[-0.17 \text { to }-0.002]^{\circ} \mathrm{C}, p=0.042\right)$ and $10-15 \mathrm{~min}(-0.10$ $\left.[-0.18 \text { to }-0.02]^{\circ} \mathrm{C}, p=0.009\right)$ of recovery compared to the first $0-5 \mathrm{~min}$ of recovery, indicating an initial delay in the ability of an ice vest to reduce $T_{\text {re }}$. Mean delta and individual data for $T_{\text {re }}$ is visualized in Table 1 and Figure 2, respectively.

During time-limited recovery, the ice vest was more effective at reducing $\bar{T}_{\mathrm{sk}}$ compared to both control $(-1.07[-2.00$ to $\left.-0.13]^{\circ} \mathrm{C}, p=0.021\right)$ and single-hand cooling $(-1.07$ [ -2.01 to $-0.14]^{\circ} \mathrm{C}, p=0.020$ ). More specifically, the ice vest heightened recovery of $\bar{T}_{\mathrm{sk}}$ within the first $5 \mathrm{~min}$ of recovery compared to both control $\left(-0.74[-1.12 \text { to }-0.36]^{\circ} \mathrm{C}, p<0.0001\right)$ and single-hand cooling $\left(-0.69[-1.07 \text { to }-0.30]^{\circ} \mathrm{C}, p<0.0001\right)$. The first $5 \mathrm{~min}$ of recovery appear to be especially important for the $\bar{T}_{\text {sk }}$ reducing effects of the ice vest, as $\bar{T}_{\text {sk }}$ was reduced more in the first $5 \mathrm{~min}$ as compared to $5-10(-0.59[-0.97$ to -0.21$\left.]^{\circ} \mathrm{C}, p=0.001\right)$ or $10-15\left(-0.61[-0.99 \text { to }-0.23]^{\circ} \mathrm{C}\right.$, $p=0.001)$ minutes. $\bar{T}_{\mathrm{sk}}$ was also more effectively reduced with ice vest application when considering prolonged exercise recovery $\left(\mathrm{REC}_{0-60}\right)$ compared to both control $(-1.62[-2.56$ to $\left.-0.68]^{\circ} \mathrm{C}, p<0.0001\right)$ and single-hand cooling $(-1.68[-2.61$ to -0.74$\left.]^{\circ} \mathrm{C}, p<0.0001\right)$. Although, the ice vest was efficient in reducing $\bar{T}_{\text {sk }}$ within the first $15 \mathrm{~min}$ of recovery, considerable further skin cooling was apparent with extending the length of vest cooling exposure $\left(\mathrm{REC}_{0-60}\right)$. For the ice vest condition, prolonged recovery elicited greater reductions in $\bar{T}_{\text {sk }}$ compared to time-limited recovery $\left(-1.29[-2.05 \text { to }-0.53]^{\circ} \mathrm{C}, p=0.001\right)$. However, $\bar{T}_{\text {sk }}$ recovery during $\mathrm{REC}_{0-15}$ accounted for $56 \%$ of the total $\bar{T}_{\text {sk }}$ recovery during the full $60 \mathrm{~min}$ recovery for the ice vest, while it only accounted for $46 \%$ of $\bar{T}_{\text {sk }}$ recovery for control and $47 \%$ for single-hand cooling. Mean delta and individual data for $\bar{T}_{\text {sk }}$ can be found in Table 1 and Figure 3, respectively.

Considering the entire recovery period $\left(\mathrm{REC}_{0-60}\right)$, an ice vest was able to more effectively recover $\bar{T}_{\mathrm{b}}$ compared to both control $\left(-0.38[-0.69 \text { to }-0.07]^{\circ} \mathrm{C}, p=0.012\right)$ and single-hand cooling $\left(-0.39[-0.70 \text { to }-0.08]^{\circ} \mathrm{C}, p=0.010\right)$, although this could not confidently be extended to the time-limited recovery window $\left(\mathrm{REC}_{0-15}\right)$. Considering the components of the timelimited recovery, an ice vest was also able to more effectively reduce $\bar{T}_{\mathrm{b}}$ compared to control specifically during the first $5 \mathrm{~min}$ of recovery $\left(-0.13[-0.23 \text { to }-0.03]^{\circ} \mathrm{C}, p=0.008\right)$, likely the result of $\bar{T}_{\text {sk }}$ reductions. Across all conditions, $\bar{T}_{\mathrm{b}}$ was recovered to a greater extent with prolonged recovery compared to timelimited recovery (control: $-0.51[-0.76 \text { to }-0.26]^{\circ} \mathrm{C}, p<0.0001$; ice vest: $-0.63[-0.89 \text { to }-0.38]^{\circ} \mathrm{C}, p<0.0001$; single-hand cooling: $\left.-0.50[-0.75 \text { to }-0.24]^{\circ} \mathrm{C}, p<0.0001\right)$. However, $\bar{T}_{\mathrm{b}}$ recovery during $\mathrm{REC}_{0-15}$ accounted for $46 \%$ of the total $\bar{T}_{\mathrm{b}}$ recovery during $\mathrm{REC}_{0-60}$ for the ice vest, while it only accounted for $36 \%$ of $\bar{T}_{\mathrm{b}}$ recovery for control and $37 \%$ for single-hand cooling. Mean delta and individual data for $\bar{T}_{\mathrm{b}}$ can be found in Table 1 and Figure 4, respectively.

Single-hand cooling did not display any significant differences compared to a non-cooling control or ice vest with regards to change in $\mathrm{S}, \bar{T}_{\mathrm{b}}, T_{\text {re }}$, or $\bar{T}_{\mathrm{sk}}$ at $\mathrm{REC}_{0-15}$ or $\mathrm{REC}_{0-60}$ of post exercise recovery.

\section{Heart Rate}

Across all conditions, HR recovery was greatest during the first $5 \mathrm{~min}$ of recovery compared to the subsequent $10 \mathrm{~min}$ but was overall greater during $\mathrm{REC}_{0-60}$ vs. $\mathrm{REC}_{0-15}$ as a function of time (see Tables 1, 2). During time-limited recovery $\left(\mathrm{REC}_{0-15}\right)$ both the ice vest $\left(-9[-15\right.$ to -3$]$ bts. $\left.\min ^{-1}, p=0.002\right)$ and single-hand cooling ( $-7[-13$ to -1$]$ bts. $\mathrm{min}^{-1}, p=0.021$ ) were able to recover HR more effectively compared to control however, only the ice vest was able to recover HR more effectively compared to control $\left(-7[-13\right.$ to -1$]$ bts. $\mathrm{min}^{-1}$, $p=0.029)$ during the prolonged recovery window $\left(\mathrm{REC}_{0-60}\right)$. Mean delta and individual data for HR is visualized in Table 1 and Figure 5, respectively. 
TABLE 1 | Delta mean [95\% confidence interval] rectal temperature $\left(T_{\text {re }}\right)$, skin temperature $\left(\bar{T}_{\text {sk }}\right)$, body temperature $\left(\bar{T}_{\mathrm{b}}\right)$, stored heat $(S)$, heart rate $(H R)$, and thermal sensation (TS) during prolonged recovery ( $\left.\mathrm{REC}_{0-60}\right)$, and time-limited recovery $\left(\mathrm{REC}_{0-15}\right)$ with 5 min block component analysis $\left(\mathrm{REC}_{0-5}, \mathrm{REC}_{5-10}, \mathrm{REC}_{10-15}\right)$ when using a non-cooled control, ice vest, and single hand-cooling during heated exercise recovery.

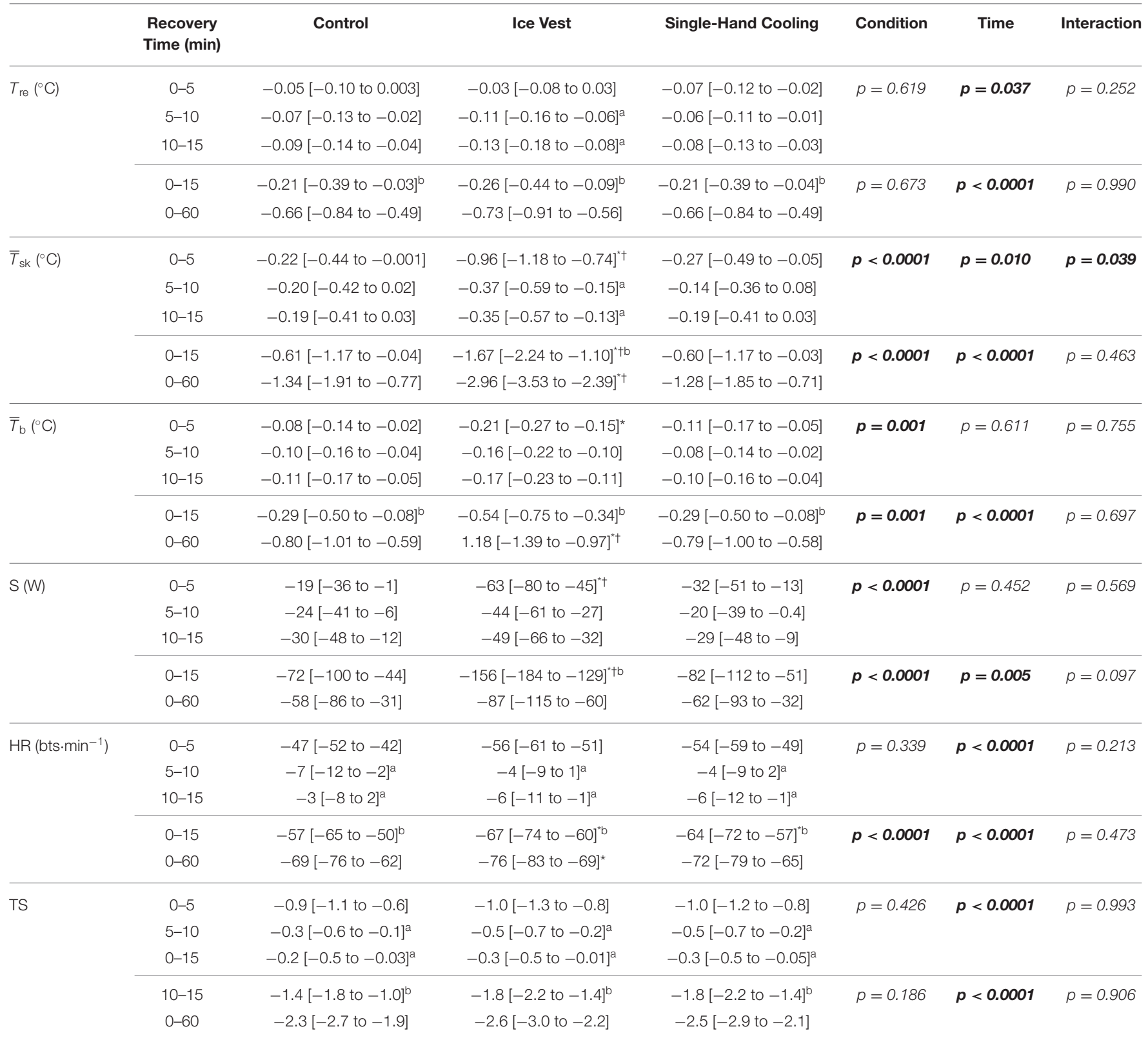

Mixed Linear Model Covariates: $T_{r e}: 38.29^{\circ} \mathrm{C} ; \bar{T}_{\text {sk }}: 37.32^{\circ} \mathrm{C}$; $\bar{T}_{b}: 38.09^{\circ} \mathrm{C}$; HR: 159 (bts.min ${ }^{-1}$ ); TS: 6.8; S: 87 W.

a Significantly $(p<0.05)$ different than $0-5 \mathrm{~min}$.

${ }^{b}$ Significantly $(p<0.05)$ different than 0-60 min.

*Significantly different than control $(p<0.05)$.

${ }^{\dagger}$ Significantly different than single-hand cooling $(p<0.05)$.

Bold values represent significant $(p<0.05)$ main and/or interaction effects.

\section{Perceptual Index}

Across all conditions, reductions in TS were greatest during the first $5 \mathrm{~min}$ of recovery compared to the subsequent $10 \mathrm{~min}$ but were overall greater during $\mathrm{REC}_{0-60}$ vs. $\mathrm{REC}_{0-15}$ as a function of time. No differences between conditions existed with regards to TS reduction across time-limited or prolonged recovery $(p=0.906)$. Mean delta data for TS is presented in Table 1.

\section{Body Fluid Balance}

Pre-post fluid loss, as indicated by change in nude body mass, was similar across the three 


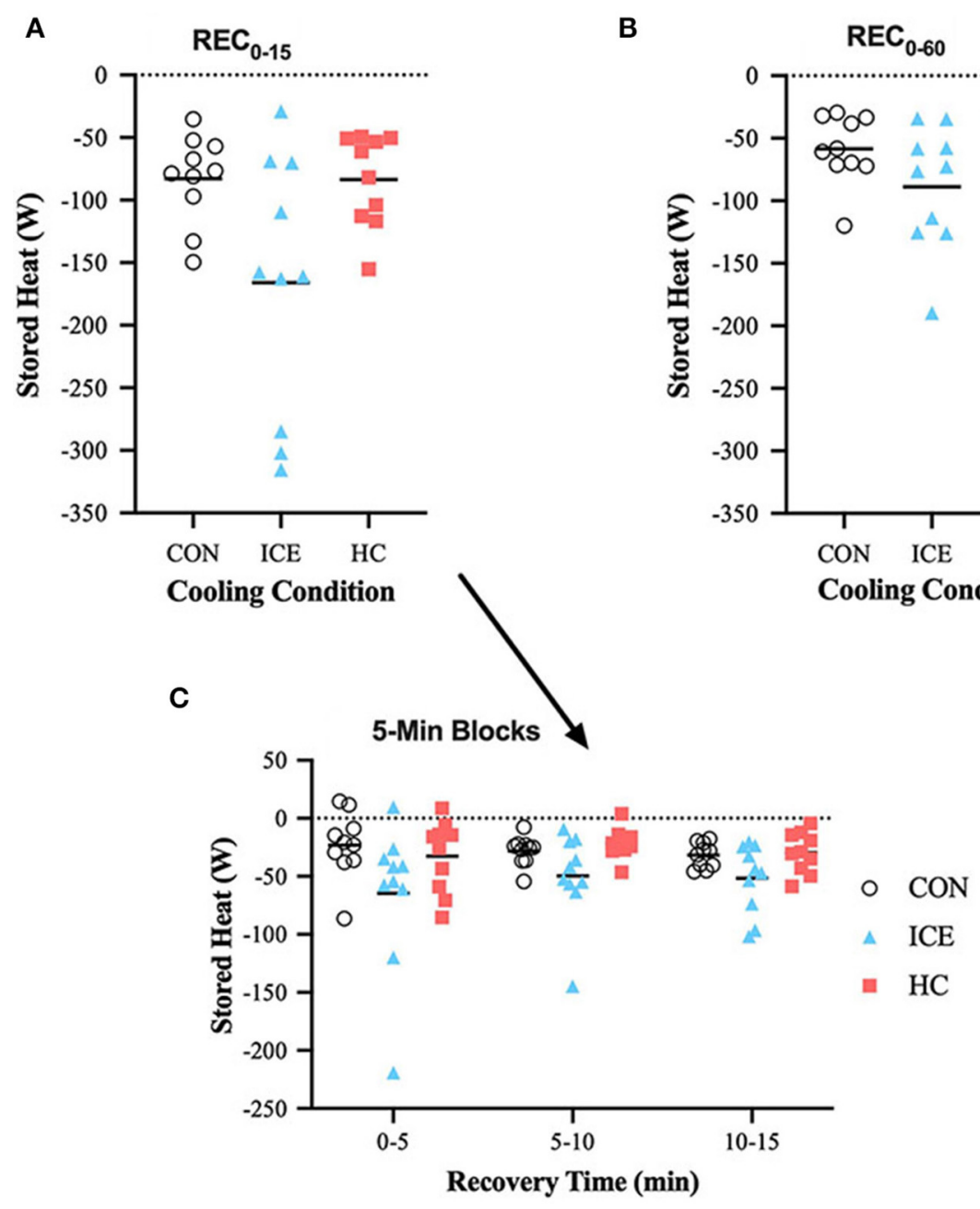

FIGURE 1 | Mean (bar) and individual delta stored heat (S) during REC $\mathrm{R}_{-15}$ (A), REC $\mathrm{C}_{-60}$ (B), and 5-min blocks during REC $\mathrm{C}_{-15}$ (C) when using ice vest (ICE), single-hand cooling $(\mathrm{HC})$, and non-cooled control $(\mathrm{CON})$ during heated exercise recovery.

trials (single-hand cooling: $1.19 \pm 0.56 \%$, ice vest: $1.27 \pm 0.47 \%$, non-cooling control: $1.40 \pm 0.68 \%$; $p=0.490)$.

\section{DISCUSSION}

The primary aim of this study was to investigate the effectiveness of time-limited and long-term active cooling compared to passive recovery following prolonged submaximal exercise in the heat with sport-mimicking recovery conditions. Neither the ice vest nor single-hand cooling were able to improve $T_{\text {re }}$ or TS recovery at any time post-exercise compared to a non-cooling control. However, during time-limited recovery an ice vest induced greater recovery of $\bar{T}_{\text {sk }}$ and improved heat loss compared to a non-cooling control, both of which were apparent within the first 5 min of recovery. Reductions in $\bar{T}_{\text {sk }}$ were also greater with an ice vest compared to a non-cooling control when considering the prolonged $60 \mathrm{~min}$ recovery $\left(\mathrm{REC}_{0-60}\right)$, translating into greater reductions in calculated mean body temperature. Single-hand cooling was unable to augment recovery of $\bar{T}_{\mathrm{b}}, \mathrm{S}$, or $\bar{T}_{\mathrm{sk}}$ compared to a non-cooling control with any investigated recovery length. Yet, both the ice vest and single-hand cooling enhanced HR recovery compared to a non-cooling control early during exercise recovery $\left(\mathrm{REC}_{0-15}\right)$, although this remained distinguishable into prolonged recovery $\left(\mathrm{REC}_{0-60}\right)$ only for the ice vest (see Table 2).

A secondary aim of this study was to examine thermophysiological and perceptual differences during heated recovery between negative pressure hand cooling and the application of an ice vest. An ice vest was no more effective at reducing $T_{\text {re }}$, TS, or HR compared to single-hand cooling. That said, compared to single-hand cooling, an ice vest more effectively reduced $\bar{T}_{\text {sk }}$ during both time-limited $\left(\mathrm{REC}_{0-15}\right)$ and prolonged recovery $\left(\mathrm{REC}_{0-60}\right)$. The time-limited recovery reduction in $\bar{T}_{\text {sk }}$ elicited by an ice vest concurrently enhanced heat loss compared to single-hand cooling (see Table 2). 


\section{A}

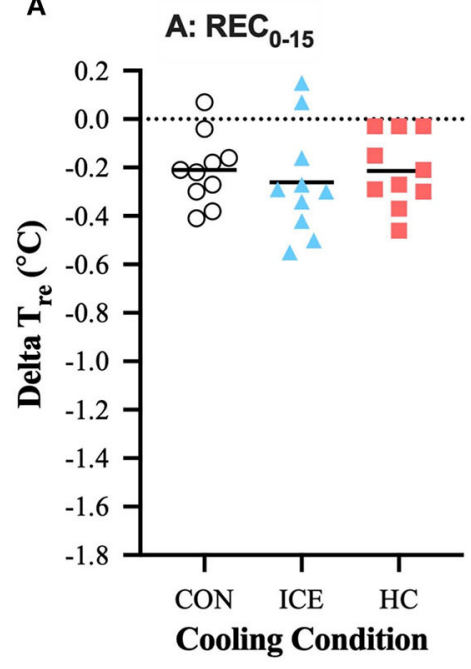

B

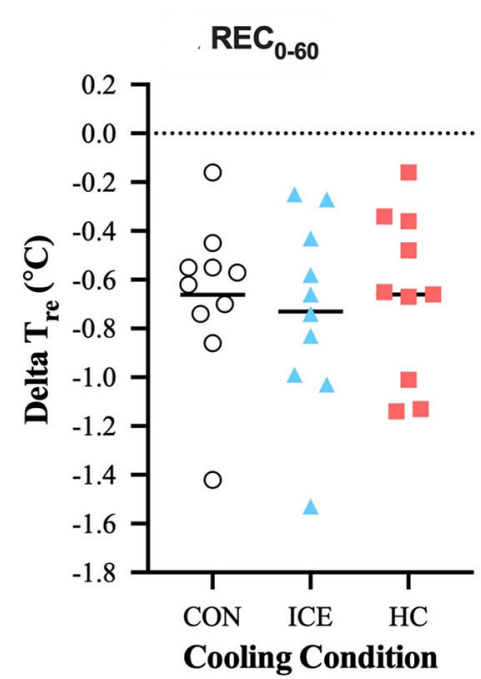

C

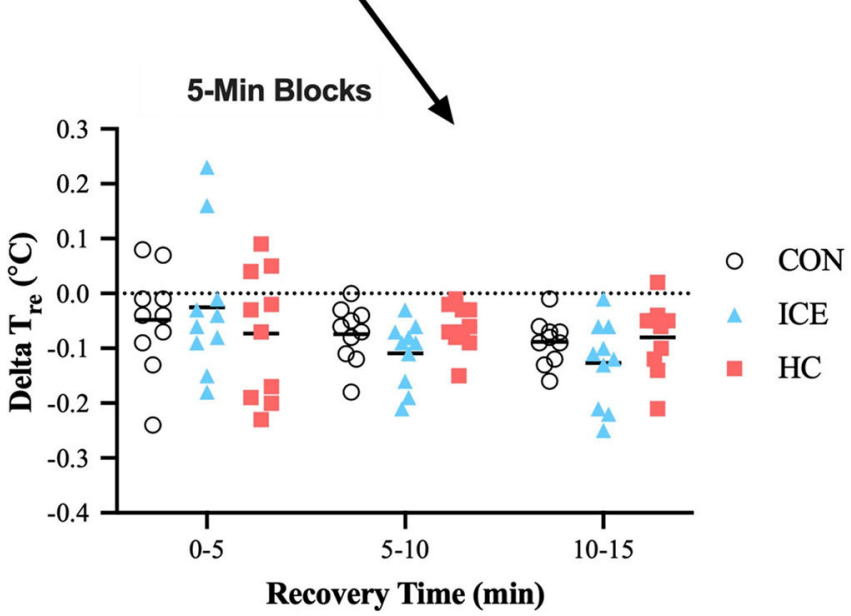

FIGURE 2 | Mean (bar) and individual delta rectal temperature ( $T_{\text {re }}$ ) during $\mathrm{REC}_{0-15}$ (A), REC $\mathrm{C}_{0-60}$ (B), and 5-min blocks during REC $\mathrm{C}_{0-15}$ (C) when using ice vest (ICE), single-hand cooling $(\mathrm{HC})$, and non-cooled control $(\mathrm{CON})$ during heated exercise recovery.

\section{Exercise Recovery: Ice Vest Influence on Thermoregulatory Recovery}

Wearing an ice vest during time-limited heated exercise recovery enhanced heat loss and $\bar{T}_{\text {sk }}$ reductions compared to a non-cooling control The application of $0^{\circ} \mathrm{C}$ ice packs to the temperature elevated skin provided a widened heat loss gradient that facilitated greater heat loss from the blood perfusing the skin. Due to the $30 \%$ contribution of the chest thermocouple to the $\bar{T}_{\text {sk }}$ calculation (Ramanathan, 1964), the enhanced reduction of $\bar{T}_{\text {sk }}$ may be a more accurate representation of the change in chest skin temperature than a change in whole body skin temperature. Despite this influence, a lowered $T_{\text {sk }}$ at the chest likely still has an impact on thermoregulatory function via peripheral thermoregulatory mechanisms (Huizenga et al., 2004).

Interestingly, the improvements in $\bar{T}_{\mathrm{sk}}$ reduction by the phase-changing ice vest were not able to translate to a significantly greater recovery of $T_{\text {re }}$ compared to a non-cooling control during heated exercise recovery. Similar investigations support this notion that phase-changing cool inserts may be effective at cooling the skin but tend to have a substantially smaller effect on measured deep body temperature (Duffield and Marino, 2007; Barwood et al., 2009). One possible explanation lies in the large surface area covered by the vest $(\sim 26 \%$ of total body surface area) which may impede immediate postexercise evaporative cooling that would otherwise contribute to reductions in deeper body temperature (Barwood et al., 2009). As subjects were cooled by the ice vest, so too the ice vest was warmed by the subject and ambient environment, further reducing heat loss gradients and therefore cooling magnitude over time. Cooling investigations using temperaturemaintained liquid perfused vests suggest they may be more viable to manipulate deeper body temperature (Balldin et al., 2007; Amorim et al., 2010), however it may be argued that maintenance of water temperature or other liquid-perfused vests may be logistically difficult, especially when attempting to cool in thermally-challenging environmental conditions. Despite the 


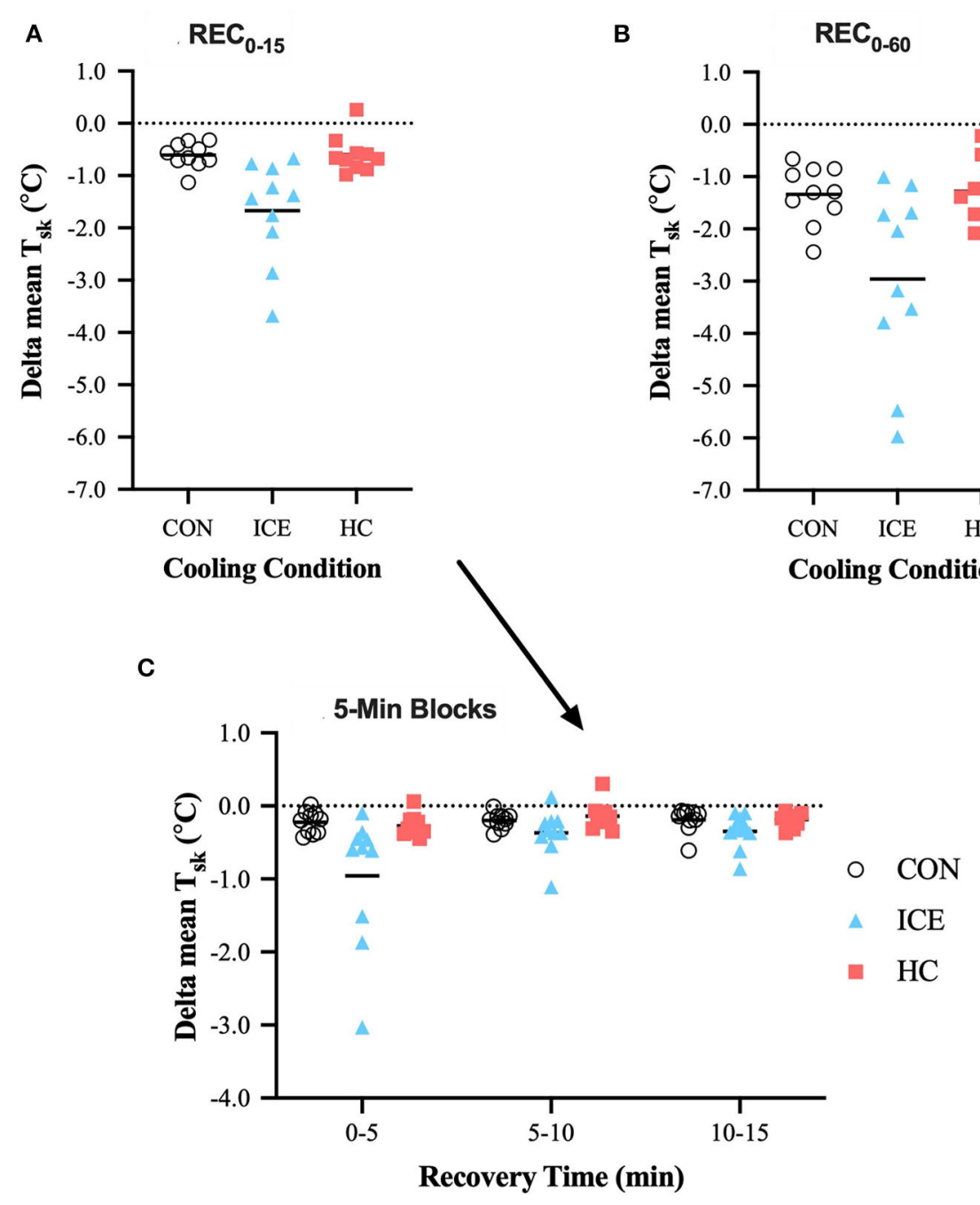

FIGURE 3 | Mean (bar) and individual delta mean skin temperature ( $T_{\text {sk }}$ ) during $\mathrm{REC}_{0-15}$ (A), REC $\mathrm{C}_{0-60}$ (B), and 5-min blocks during $\mathrm{REC}_{0-15}$ (C) when using ice vest (ICE), single-hand cooling ( $\mathrm{HC})$, and non-cooled control (CON) during heated exercise recovery.

core temperature independent perceptual link between TS and localized $\bar{T}_{\text {sk }}$ (Schlader et al., 2011), TS was also not significantly altered by the ice vest. Personal subjective bias resulting from differences in heat tolerance and psychological bias may lead to overestimation of thermal relief upon cessation of exercise.

Wearing an ice vest reduced HR beyond that of a noncooling control during both time-limited and prolonged heated recovery. A reduction in peripheral vasodilation, due to ice vest application, likely results in an increase in central venous pressure via a shift of cutaneous blood into the thoracic vasculature. This shift simultaneously stimulates high arterial pressure and low cardiopulmonary pressure baroreflexes, effectively eliciting an increase in cardiac vagal tone (Pump et al., 2001) and resultant expedited decrease in HR beyond that demonstrated by passive exercise recovery. This hypothesis along with the much smaller $T_{\text {re }}$ recovery within the first $5 \mathrm{~min}$ of recovery for the ice vest further supports the notion that reactive peripheral vasoconstriction, depending on the magnitude as reflective of cold severity, may to some extent reduce the immediate cooling capability of the ice vest. However, it may be argued that the phase-changing nature of the ice vest reduces the impact of this initial vasoconstrictive clamping as the ice packs melt. Similarly to the ice vest, single-hand cooling was able to reduce $\mathrm{HR}$ beyond that of the non-cooling control after $15 \mathrm{~min}$ of exposure. This is to some extent surprising, but may indicate that even single hand cooling is sufficient to initiate reflexive baroreceptor controlled increases in cardiac vagal tone.

An ice vest was superior to single-hand cooling in reducing $\bar{T}_{\text {sk }}$ during $\mathrm{REC}_{0-5}, \mathrm{REC}_{0-15}$, and $\mathrm{REC}_{0-60}$ and heat storage during time-limited recovery. This may be explained by the ice vest's greater surface area ( $\sim 26$ vs. $1 \%$ of total body surface area), upon which the widened cooling gradient is applied. Further evaluation of the rate of $T_{\text {re }}$ recovery for all conditions, especially during the first 5 min of recovery, indicates that singlehand cooling may be the quickest, of the strategies tested, to initially reduce $T_{\text {re }}$ (single-hand cooling: $-0.015^{\circ} \mathrm{C} \cdot \mathrm{min}^{-1}$, ice vest: $-0.007^{\circ} \mathrm{C} \cdot \mathrm{min}^{-1}$, non-cooling control: $-0.010^{\circ} \mathrm{C} \cdot \mathrm{min}^{-1}$ ). The rate of cooling by single-hand cooling in the present study 


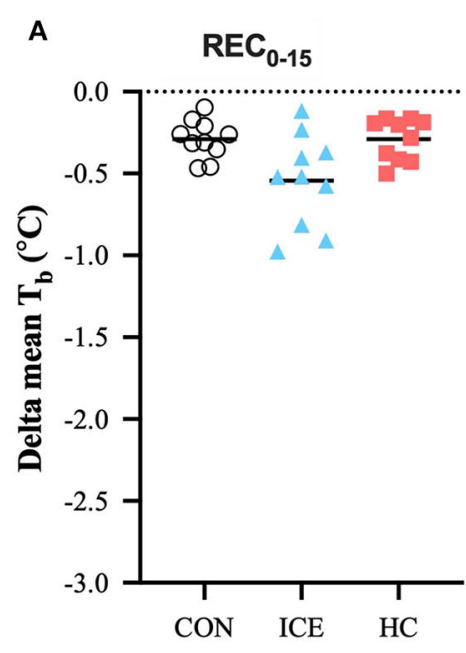

Cooling Condition

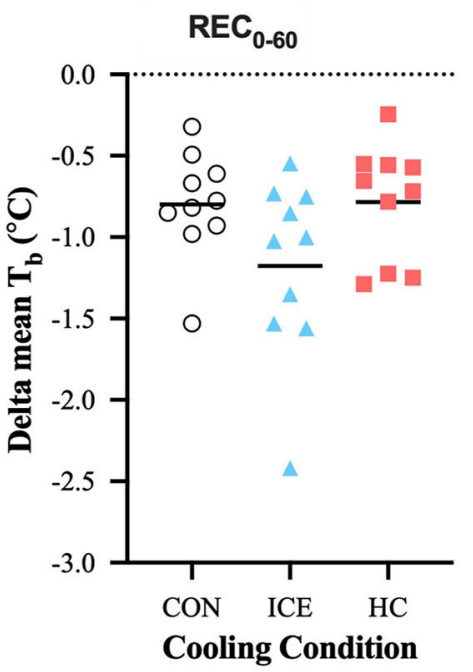

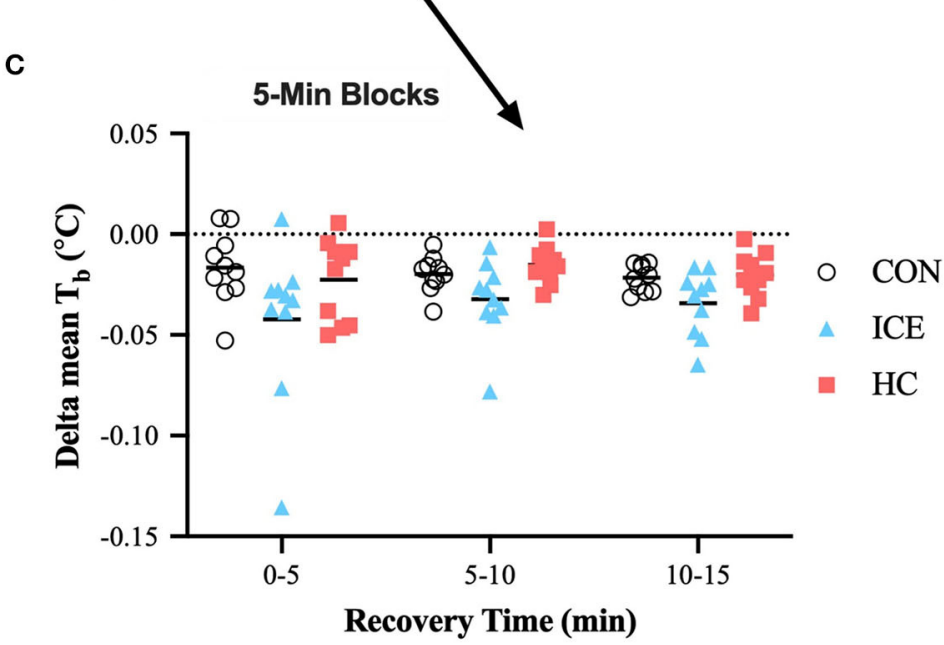

FIGURE 4 | Mean (bar) and individual delta mean body temperature $\left(T_{b}\right)$ during $R C_{0-15}$ (A), $R C_{0-60}$ (B), and 5-min blocks during $R E C_{0-15}$ (C) when using ice vest (ICE), single-hand cooling (HC), and non-cooled control (CON) during heated exercise recovery.

is similar to that reported in previous literature investigating cooling of one hand $\left(-0.017{ }^{\circ} \mathrm{C} \cdot \mathrm{min}^{-1}\right)($ Grahn et al., 2009). The comparatively small rate of $T_{\text {re }}$ change with the ice vest supports the likelihood of reactive cutaneous vasoconstriction and/or a sudden reduction in evaporative cooling due to the surface area covered by vest application. Two subjects (Figure 2) demonstrated continued rise in $T_{\text {re }}$ despite $5 \mathrm{~min}$ of vest application indicating that although a quick change in skin temperature did tend to occur within the first $5 \mathrm{~min}$ (Figure 3) it likely contributed to some degree of vasoconstriction and/or lack of evaporative cooling capability. While an ice vest was slower to recover $T_{\mathrm{re}}$ immediately upon application compared to single-hand cooling and a noncooling control, the ice vest demonstrated superior cooling rates at both $5-10$ (single-hand cooling: $-0.012^{\circ} \mathrm{C} \cdot \mathrm{min}^{-1}$, ice vest: $-0.022^{\circ} \mathrm{C} \cdot \mathrm{min}^{-1}$, non-cooling control: $-0.015^{\circ} \mathrm{C} \cdot \mathrm{min}^{-1}$ ) and $10-15 \mathrm{~min}$ (single-hand cooling: $-0.017^{\circ} \mathrm{C} \cdot \mathrm{min}^{-1}$, ice vest: $-0.025^{\circ} \mathrm{C} \cdot \mathrm{min}^{-1}$, non-cooling control: $\left.-0.018^{\circ} \mathrm{C} \cdot \mathrm{min}^{-1}\right)$. Combined with the larger influence of an ice vest on thermo-physiological responses during heated exercise recovery, these rates indicate that, of the methods tested, an ice vest may be the most applicable to achieve effective cooling during time-limited recovery.

\section{Exercise Recovery: Single-Hand Cooling Influence on Thermoregulatory Recovery}

Single-hand cooling using a negative pressure device was unable to enhance heated exercise thermoregulatory recovery beyond that of the non-cooling control regardless of application length (15 vs. $60 \mathrm{~min}$ ). A similar investigation capable of minimally increasing $T_{\text {re }}$ to $37.72^{\circ} \mathrm{C}$ also indicated a single-hand cooling device was no more effective at decreasing $T_{\text {re }}$ following heated $\left(35^{\circ} \mathrm{C}, 85 \% \mathrm{RH}\right)$ exercise than control or vest conditions (Balldin et al., 2007). This minor thermal gain likely stimulated a smaller volume of blood to the skin providing a very small heat dissipation gradient, thereby minimizing the influence of the hand-cooling device. Still, even with much greater 
TABLE 2 | Visual summary of thermo-physiological and thermal perceptual differences between cooling conditions across immediate (REC $\left.\mathrm{C}_{0-5}\right)$, time-limited (REC $\left.\mathrm{C}_{0-15}\right)$, and prolonged recovery $\left(\mathrm{REC}_{0-60}\right)$.

\begin{tabular}{|c|c|c|c|c|c|c|c|c|c|}
\hline & \multicolumn{3}{|c|}{ Ice Vest > Control } & \multicolumn{3}{|c|}{ Single-Hand Cooling > Control } & \multicolumn{3}{|c|}{ Ice Vest $>$ Single-Hand Cooling } \\
\hline & $0-5$ & $0-15$ & $0-60$ & $0-5$ & $0-15$ & $0-60$ & $0-5$ & $0-15$ & $0-60$ \\
\hline $\begin{array}{l}T_{\mathrm{re}} \\
\left({ }^{\circ} \mathrm{C}\right)\end{array}$ & & & & & & & & & \\
\hline $\begin{array}{l}\bar{T}_{\mathrm{b}} \\
\left({ }^{\circ} \mathrm{C}\right)\end{array}$ & & & & & & & & & \\
\hline $\begin{array}{c}\mathrm{HR} \\
\text { (bts.min- }\end{array}$ & & & & & & & & & \\
\hline TS & & & & & & & & & \\
\hline
\end{tabular}

Gray boxes indicate significant difference $(p<0.05)$ for the column described difference in recovery magnitude; White boxes indicate a lack of significant difference $(p>0.05)$ for the column described difference in recovery magnitude; $0-5,0-5 \mathrm{~min}$ of recovery; $0-15,0-15 \mathrm{~min}$ of recovery; $0-60,0-60$ min of recovery.

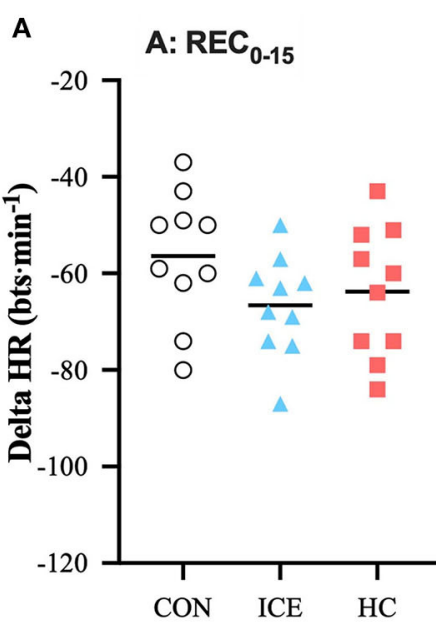

Cooling Condition

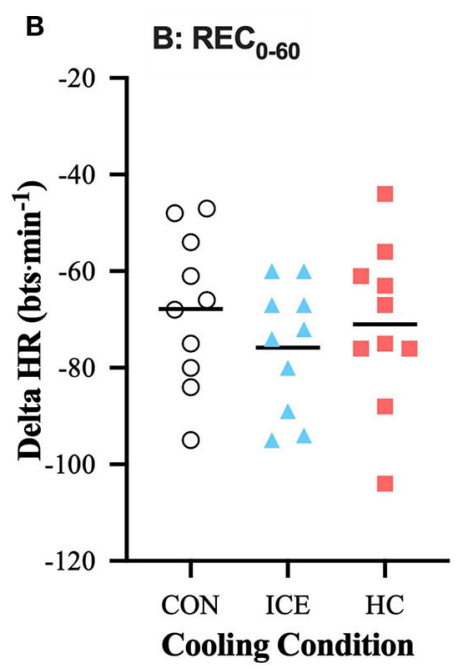

C

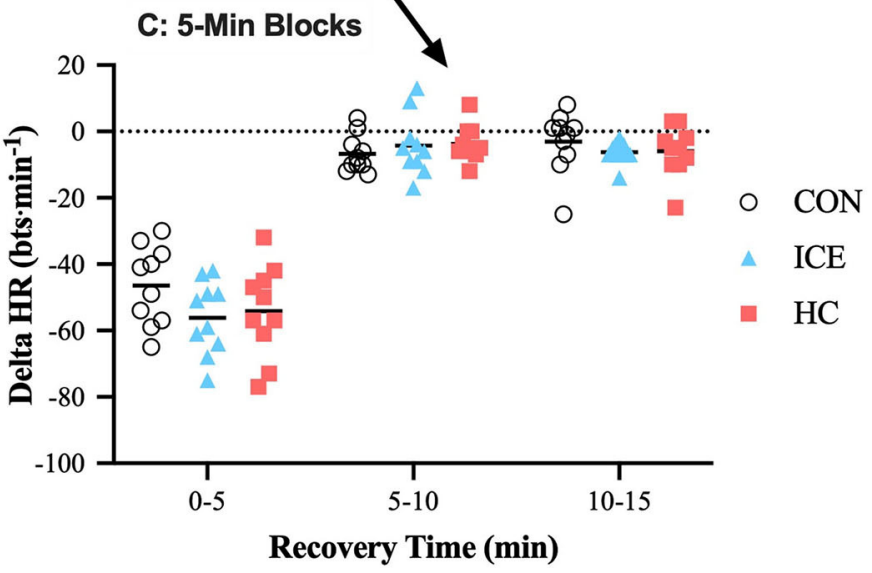

FIGURE 5 | Mean (bar) and individual delta heart rate (HR) during REC $\mathrm{R}_{0-15}$ (A), REC $\mathrm{C}_{-60}$ (B), and 5-min blocks during REC ${ }_{0-15}$ (C) when using ice vest (ICE), single-hand cooling $(\mathrm{HC})$, and non-cooled control $(\mathrm{CON})$ during heated exercise recovery. 
thermoregulatory stress, the result of both a higher ambient temperature $\left(42^{\circ} \mathrm{C}\right)$ and heat loss retardant clothing, negative pressure single hand cooling was no more effective at deep body temperature recovery following exercise $\left(T_{\mathrm{re}} 38.5^{\circ} \mathrm{C}\right)$ than a noncooling control (Amorim et al., 2010). The significantly lower body surface area cooled with single-hand cooling vs. a torsoencompassing vest may help to explain single-hand cooling's thermoregulatory shortcomings as both the present study and Amorim et al. indicate vest application, a phase-changing ice and cold water perfused vest, respectively, as a superior cooling technique. The unique presence of a continued environmental heat stress during recovery with the cooling device may therefore reduce the overall likelihood of single-hand cooling to enhance core temperature recovery.

Core temperature at cessation of exercise, and therefore start of exercise recovery, likely also plays a key role in the efficacy of single-hand cooling as a thermoregulation enhancing device. As both core and skin temperatures tend to rise commensurately (Gleeson, 1998), a greater achieved core temperature is likely reflective of a greater skin temperature, effectively providing a widened heat loss gradient when a cooling device is applied that favors improved heat loss. Firefighters recovering from heavy physical work in $36^{\circ} \mathrm{C}, 44 \% \mathrm{RH}$ performed to a $T_{\text {re }}$ of $39^{\circ} \mathrm{C}$ cooled $144 \%$ more with single-hand cooling for 40 min compared to passive cooling (Zhang et al., 2009). Furthermore, individuals heated using $39.3^{\circ} \mathrm{C} 38 \% \mathrm{RH}$ ambient conditions paired with vigorous walking to a $T_{\text {re }}$ of $39.44^{\circ} \mathrm{C}$ experienced enhanced $T_{\text {re }}$ recovery following a $20 \mathrm{~min}$ application of an $\sim 17^{\circ} \mathrm{C}$ cooling device on each hand (Adams et al., 2016). Barwood et al. (2009) additionally investigated a two-hand cold water immersion exercise recovery strategy that induced heat loss of $\sim 162 \mathrm{~W}$ after $10-15 \mathrm{~min}$ and was effective at augmenting reduction in $T_{\text {re }}$ compared to a non-cooling control condition (heat loss $\sim 99 \mathrm{~W}$ ). Heat loss induced via this dual hand cold water immersion is similar to that induced by the ice vest in the current investigation over a similar $15 \mathrm{~min}$ time period, $\sim 166 \mathrm{~W}$, and yet the ice vest was unable to elicit enhanced $T_{\text {re }}$ recovery. As heat storage is determined utilizing a change in $\bar{T}_{\mathrm{b}}$, it appears that dual hand cooling and ice vest application may modulate calculated body temperature divergently within the first $15 \mathrm{~min}$ of cooling, with dual hand cooling having greater influence on $T_{\text {re }}$ hypothesized to result from significant cooling of the blood, without significant change in $\bar{T}_{\mathrm{sk}}$ and vice versa for ice vest application.

Single-hand cooling in our investigation induced heat loss of $\sim 84 \mathrm{~W}$, roughly half that demonstrated by dual-handed immersion at the same $\sim 17^{\circ} \mathrm{C}$ exposure temperature (Barwood et al., 2009), over the first $15 \mathrm{~min}$ of recovery, indicating the importance of maximizing the amount of surface area cooled to thermoregulatory recovery. Additionally as hand water immersion sans the use of a negative pressure vacuum seal was successful in augmenting $T_{\text {re }}$ recovery, the necessity or usefulness of this feature to offset otherwise inhibiting vasoconstriction is thought questionable. Overall, literature suggests the influence of cooling with or without a vacuum on heat loss appears small ( $\sim 12 \mathrm{~W}$ ) (Kuennen et al., 2010). Ultimately, the cooling effectiveness of cold water hand immersion is determined by the maintenance of peripheral blood flow as well as the heat loss gradient magnitude between the skin and the immersion water. Water of $\sim 15^{\circ} \mathrm{C}$ is sufficient to induce peripheral vasoconstriction in individuals with maintained deep body temperatures (Tipton et al., 1993), rendering the selected hand cooling temperature of the current study near optimal. Collectively, literature that has been successful at modulating $T_{\text {re }}$ during recovery in the heat beyond that possible by passive cooling demonstrates that hand cooling may be capable of greater cooling compared to a non-cooling control. It does appear that a few conditions may be necessary to facilitate: (1) $T_{\text {re }}$ of $\sim 39^{\circ} \mathrm{C}$ that facilitates a larger heat loss gradient and reduces the influence of peripheral vasoconstriction; and (2) the use of dual hand vs. single hand cooling to maximize the amount of total body surface area cooled.

Methodological limitations to measurement of thermoregulatory variables must also be considered. Postexercise $T_{\text {re }}$ values indicate a similar level of thermal stress between our three separate trial conditions. Similar literature places this exercise thermal stress in a "moderately high" category. Other investigations, utilizing $T_{\text {re }}$, have successfully produced a larger thermal gain, achieving temperatures as high as $39-39.44^{\circ} \mathrm{C}$ (Zhang et al., 2009; Adams et al., 2016). These temperatures were set as exercise end-points rather than a product of a given duration of exercise time and were accomplished with a combination of both environmental and clothing manipulation. We chose instead to impose a time relative end-point to exercise $(60 \mathrm{~min})$ for two reasons: (1) The subject population recruited consisted primarily of natives to a variable climate region with little exposure to the experience of performing exercise in considerable heat. For this reason, two preliminary subjects exhibited significant difficulty in completing the exercise task to a core temperature $>38.5^{\circ} \mathrm{C}$; (2) In a real-world scenario, the likelihood of athletes or occupational workers performing the same duration of physical work is much greater than achieving an identical exercise core temperature. Numerous investigators have provided data to suggest the inability of $T_{\text {re }}$ to respond as readily to rapid changes in core temperature compared to esophageal temperature (Lee et al., 2000; Easton et al., 2007). While subjects wore heavy heat retardant uniforms after exercising in the heat to an esophageal temperature of $38.8^{\circ} \mathrm{C}$, a single-hand cooling device elicited significantly lower esophageal and skin temperatures from 15 to $50 \mathrm{~min}$ of exercise recovery (Kuennen et al., 2010). Esophageal temperatures may offer improved sensitivity and responsiveness over rectal temperatures, especially as rate of cooling is prioritized. Esophageal temperature, though, does pose significant practicality concerns as many subjects struggle to place and tolerate the temperature probe. Due to logistical difficulties with efficiently replicating wind velocity, it was omitted from the current design. Wind velocity should, however, be considered as a variable that may reduce or otherwise alter the efficiency of the investigated cooling devices.

\section{CONCLUSIONS}

Wearing an ice vest but not single hand-cooling, using a cold water low pressure vacuum device, was effective at reducing thermo-physiological strain during both time-limited 
and prolonged heated exercise recovery. When a prolonged heated recovery time is accessible, an ice vest is superior to both passive and single-hand cooling to reduce mean body and skin temperatures. An ice vest also appears efficacious in reducing mean skin temperature after as little as $15 \mathrm{~min}$ of application, making its use specifically advantageous for time-limited sport or occupational recovery. Although the lower mean skin temperatures after 15 and $60 \mathrm{~min}$ were not able to elicit a significantly lower $T_{\text {re }}$ or a reduced thermal strain, this peripheral activity may still impact overall thermoregulatory function. With moderately, rather than severely, elevated core temperatures, time-limited sport thermoregulatory recovery in the heat is likely enhanced with the use of techniques that encompass a larger degree of body surface area, like an ice vest. This may be particularly meaningful during sporting halftime to proactively offset progressive increases in thermal stress during a second-half physical effort. Further research is necessary to pinpoint the exact environmental conditions and level of hyperthermia for which single-hand cooling or phase-changing ice vest application may be most beneficial.

\section{DATA AVAILABILITY STATEMENT}

The raw data supporting the conclusions of this article will be made available by the authors, without undue reservation.

\section{REFERENCES}

Adams, W. M., Hosokawa, Y., Adams, E. L., Belval, L. N., Huggins, R. A., and Casa, D. J. (2016). Reduction in body temperature using hand cooling versus passive rest after exercise in the heat. J. Sci. Med. Sport 19, 936-940. doi: $10.1016 /$ j.jsams.2016.02.006

Amorim, F. T., Yamada, P. M., Robergs, R. A., and Schneider, S. M. (2010). Palm cooling does not reduce heat strain during exercise in a hot, dry environment. Appl. Physiol. Nutr. Metab. 35, 480-489. doi: 10.1139/H10-040

Balldin, U., Whitmore, J., Harrison, R., Fisher, D., Fischer, J., and Stork, R. (2007). "The effects of a palm cooling device and a cooling vest during simulated pilot heat stress," in Air Force research laboratory: Interim Report for October 2005 to January 2007. Brooks-City-Base, TX.

Barwood, M. J., Davey, S., House, J. R., and Tipton, M. J. (2009). Post-exercise cooling techniques in hot, humid conditions. Eur. J. Appl. Physiol. 107, 385-396. doi: 10.1007/s00421-009-1135-1

Bergersen, T. (1993). A search for arteriovenous anastomoses in human skin using ultrasound Doppler. Acta Physiol. Scand. 147, 195-201. doi: 10.1111/j.1748-1716.1993.tb09489.x

Borg, G., and Linderholm, H. (1967). Perceived exertion and pulse rate during graded exercise in various age groups. Acta Med. Scand. 181, 194-206. doi: 10.1111/j.0954-6820.1967.tb12626.x

Cadarette, B. S., Levine, L., Kolka, M. A., Proulx, G. N., Correa, M. M., and Sawka, M. N. (2002). Heat strain reduction by ice-based and vapor compression liquid cooling systems with a toxic agent protective uniform. Aviat. Space Environ. Med. 73, 665-672.

Casa, D. J., DeMartini, J. K., Bergeron, M. F., Csillan, D., Eichner, E. R., Lopez, R. M., et al. (2015). National Athletic Trainers' Association position statement: exertional heat illnesses. J. Athl. Train. 50, 986-1000. doi: 10.4085/1062-6050-50.9.07

Colin, J., and Houdas, Y. (1965). Initiation of sweating in man after abrupt rise in environmental temperature. J. Appl. Physiol. 20, 984-990. doi: 10.1152/jappl.1965.20.5.984

Coris, E. E., Ramirez, A. M., and Van Durme, D. J. (2004). Heat illness in athletes. Sports Med. 34, 9-16. doi: 10.2165/00007256-200434010-00002

\section{ETHICS STATEMENT}

The studies involving human participants were reviewed and approved by Human Subjects Institutional Review Board Western Michigan University. The patients/participants provided their written informed consent to participate in this study.

\section{AUTHOR CONTRIBUTIONS}

AS performed the experiments and collected all participant data. AS and RS conceived and designed the experiments, analyzed the data, summarized the results, wrote and revised the manuscript. All authors contributed to the article and approved the submitted version.

\section{ACKNOWLEDGMENTS}

This research was supported in part by an appointment to the Department of Defense (DOD) Research Participation Program administered by the Oak Ridge Institute for Science and Education (ORISE) through an interagency agreement between the U.S. Department of Energy (DOE) and the DOD. ORISE is managed by ORAU under DOE contract number DESC0014664.
Duffield, R., and Marino, F. E. (2007). Effects of pre-cooling procedures on intermittent-sprint exercise performance in warm conditions. Eur. J. Appl. Physiol. 100, 727-735. doi: 10.1007/s00421-007-0468-x

Easton, C., Fudge, B. W., and Pitsiladis, Y. P. (2007). Rectal, telemetry pill and tympanic membrane thermometry during exercise heat stress. J. Therm. Biol. 32, 78-86. doi: 10.1016/j.jtherbio.2006.10.004

Gagge, A. P., Stolwijk, J., and Hardy, J. (1967). Comfort and thermal sensations and associated physiological responses at various ambient temperatures. Environ. Res. 1, 1-20. doi: 10.1016/0013-9351(67)90002-3

Gleeson, M. (1998). Temperature regulation during exercise. Int. J. Sports Med. 19(S2), S96-S99. doi: 10.1055/s-2007-971967

Grahn, D., Dillon, J., and Heller, H. (2009). Heat loss through the glabrous skin surfaces of heavily insulated, heat-stressed individuals. J. Biomech. Eng. 131:071005. doi: 10.1115/1.3156812

Grahn, D. A., Cao, V. H., and Heller, H. C. (2005). Heat extraction through the palm of one hand improves aerobic exercise endurance in a hot environment. J. Appl. Physiol. 99, 972-978. doi: 10.1152/japplphysiol.00093.2005

Grahn, D. A., Cao, V. H., Nguyen, C. M., Liu, M. T., and Heller, H. C. (2012). Work volume and strength training responses to resistive exercise improve with periodic heat extraction from the palm. J. Strength Condit. Res. 26, 2558-2569. doi: 10.1519/JSC.0b013e31823f8cla

House, J. (1996). "Reducing heat strain with ice-vests or hand immersion," Paper presented at the Proceedings of the 7th International Conference on Environmental Ergonomics (Jerusalem).

House, J., Lunt, H., Magness, A., and Lyons, J. (2003). Testing the effectiveness of techniques for reducing heat strain in Royal Navy nuclear, biological and chemical cleansing stations' teams. J. R. Nav. Med. Serv. 89, 27-34.

House, J. R., Lunt, H. C., Taylor, R., Milligan, G., Lyons, J. A., and House, C. M. (2013). The impact of a phase-change cooling vest on heat strain and the effect of different cooling pack melting temperatures. Eur. J. Appl. Physiol. 113, 1223-1231. doi: 10.1007/s00421-012-2534-2

Hsu, A. R., Hagobian, T. A., Jacobs, K. A., Attallah, H., and Friedlander, A. L. (2005). Effects of heat removal through the hand on metabolism and performance during cycling exercise in the heat. Canad. J. Appl. Physiol. 30, 87-104. doi: 10.1139/h0-107 
Huizenga, C., Zhang, H., Arens, E., and Wang, D. (2004). Skin and core temperature response to partial-and whole-body heating and cooling. J. Therm. Biol. 29, 549-558. doi: 10.1016/j.jtherbio.2004.08.024

Kuennen, M. R., Gillum, T. L., Amorim, F. T., Kwon, Y. S., and Schneider, S. M. (2010). Palm cooling to reduce heat strain in subjects during simulated armoured vehicle transport. Eur. J. Appl. Physiol. 108, 1217-1223. doi: 10.1007/s00421-009-1335-8

Lee, S. M. C., Williams, W. J., and Schneider, S. M. (2000). Core Temperature Measurement During Submaximal Exercise: Esophageal, Rectal, and Intestinal Temperatures. Washington, DC: National Aeronautics and Space Administration.

Lei, T. H., Cotter, J. D., Schlader, Z. J., Stannard, S. R., Perry, B. G., Barnes, M. J., et al. (2019). On exercise thermoregulation in females: interaction of endogenous and exogenous ovarian hormones. J. Physiol. 597, 71-88. doi: 10.1113/JP276233

Lorenzo, S., Halliwill, J. R., Sawka, M. N., and Minson, C. T. (2010). Heat acclimation improves exercise performance. J. Appl. Physiol. 109, 1140-1147. doi: 10.1152/japplphysiol.00495.2010

Montain, S. J., and Coyle, E. F. (1992). Influence of graded dehydration on hyperthermia and cardiovascular drift during exercise. J. Appl. Physiol. 73, 1340-1350. doi: 10.1152/jappl.1992.73.4.1340

Morris, C., Atkinson, G., Drust, B., Marrin, K., and Gregson, W. (2009). Human core temperature responses during exercise and subsequent recovery: an important interaction between diurnal variation and measurement site. Chronobiol. Int. 26, 560-575. doi: 10.1080/07420520902885981

Nybo, L., Rasmussen, P., and Sawka, M. N. (2011). Performance in the heatphysiological factors of importance for hyperthermia-induced fatigue. Compr. Physiol. 4, 657-689. doi: 10.1002/cphy.c130012

Pescatello, L. S., Riebe, D., and Thompson, P. D. (2014). ACSM's Guidelines for Exercise Testing and Prescription. Philadelphia, PA: Lippincott Williams and Wilkins.

Pump, B., Shiraishi, M., Gabrielsen, A., Bie, P., Christensen, N. J., and Norsk, P. (2001). Cardiovascular effects of static carotid baroreceptor stimulation during water immersion in humans. Am. J. Physiol. Heart Circ. Physiol. 280, H2607-H2615. doi: 10.1152/ajpheart.2001.280.6.H2607

Ramanathan, N. (1964). A new weighting system for mean surface temperature of the human body. J. Appl. Physiol. 19, 531-533. doi: 10.1152/jappl.1964.19.3.531

Schlader, Z. J., Simmons, S. E., Stannard, S. R., and Mündel, T. (2011). The independent roles of temperature and thermal perception in the control of human thermoregulatory behavior. Physiol. Behav. 103, 217-224. doi: 10.1016/j.physbeh.2011.02.002

Sunderland, C., Stevens, R., Everson, B., and Tyler, C. J. (2015). Neck-cooling improves repeated sprint performance in the heat. Front. Physiol. 6:314. doi: 10.3389/fphys.2015.00314
Tipton, M. J., Allsopp, A., Balmi, P. J., and House, J. R. (1993). Hand immersion as a method of cooling and rewarming: a short review. JR Nav Med Serv. 79, 125-131.

Travers, G., Nichols, D., Riding, N., González-Alonso, J., and Périard, J. D. (2020). Heat acclimation with controlled heart rate: influence of hydration status. Med. Sci. Sports Exerc. 52, 1815-1824. doi: 10.1249/MSS.0000000000002320

Tyler, C. J., and Sunderland, C. (2011). Neck cooling and running performance in the heat: single versus repeated application. Med. Sci. Sports Exerc. 43, 2388-2395. doi: 10.1249/MSS.0b013e318222ef72

Walker, T. B., Zupan, M. F., McGregor, J. N., Cantwell, A. R., and Norris, T. D. (2009). Is performance of intermittent intense exercise enhanced by use of a commercial palm cooling device? J. Strength Condition. Res. 23, 2666-2672. doi: 10.1519/JSC.0b013e3181b1f6a7

Wendt, D., Van Loon, L. J., and Lichtenbelt, W. D. M. (2007). Thermoregulation during exercise in the heat. Sports Med. 37, 669-682. doi: 10.2165/00007256-200737080-00002

Zhang, Y., Bishop, P. A., Casaru, C., and Davis, J. (2009). A new hand-cooling device to enhance firefighter heat strain recovery. J. Occup. Environ. Hyg. 6, 283-288. doi: 10.1080/15459620902790277

Zhang, Y., Davis, J. K., Casa, D. J., and Bishop, P. A. (2015). Optimizing cold water immersion for exercise-induced hyperthermia: a meta-analysis. Med. Sci. Sports Exerc. 47, 2464-2472. doi: 10.1249/MSS.0000000000000693

Disclaimer: The views, opinions, and/or findings contained in this article are those of the authors and should not be construed as an official United States Department of the Army position, or decision, unless so designated by other official documentation. This article is approved for public release, and distribution is unlimited.

Citations of commercial organizations and trade names in this report do not constitute an official Department of the Army endorsement or approval of the products or services of these organizations.

All opinions expressed in this paper are the author's and do not necessarily reflect the policies and views of the U.S. Army, DOD, DOE, or ORAU/ORISE.

Conflict of Interest: The authors declare that the research was conducted in the absence of any commercial or financial relationships that could be construed as a potential conflict of interest.

Copyright (c) 2021 Seeley and Sherman. This is an open-access article distributed under the terms of the Creative Commons Attribution License (CC BY). The use, distribution or reproduction in other forums is permitted, provided the original author(s) and the copyright owner(s) are credited and that the original publication in this journal is cited, in accordance with accepted academic practice. No use, distribution or reproduction is permitted which does not comply with these terms. 